\title{
eXtensible Business Reporting Language: e-Reporting?
}

\section{Mark de Haas}

SAMENVATTING Ondanks de evidente efficiencyvoordelen die het gebruik van ICT voor veel organisaties oplevert, vindt het proces van de externe verslaggeving nog grotendeels handmatig plaats. De benodigde informatie wordt binnen veel organisaties met behulp van spreadsheets verzameld. Aan het eind van elk jaar wordt het jaarverslag op papier toegezonden aan een ieder die hierin geïnteresseerd is. Willen deze gebruikers iets met de informatie doen, dan dient de informatie te worden overgezet in het eigen systeem. Deze situatie kan op korte termijn ingrijpend veranderen door de mogelijkheden van extensible Markup Language $(\mathrm{XML})$ toe te passen op delen van het rapportageproces. De gemeenschappelijke taal waarin de organisatie met haar stakeholders kan spreken, heet XBRL.

\section{Inleiding}

Als gekeken wordt naar een aantal ontwikkelingen in de Informatie- en communicatietechnologie (ICT), zijn er drie stadia te herkennen. De jaren zestig en zeventig worden gekenmerkt door de opkomst van Electronic Data Processing (EDP), het automatiseren van de administratieve processen. De daaropvolgende periode werden de overige (primaire) bedrijfsprocessen geautomatiseerd, waarbij de laatste fase werd gekenmerkt door integratie en koppeling van de verschillende systemen met behulp van Enterprise Resource Planning-pakketten (ERP).

Het tot op heden laatste stadium in de ICT wordt ook wel aangeduid met electronic business (e-business)

M. de Haas RA RE is werkzaam bij KPMG als manager bij Accounting Advisory Services. Hij is betrokken bij de ontwikkeling van XBRL sinds medio 2000. Dit artikel is op persoonlijke titel geschreven. en heeft alles te maken met de processen die zich afspelen tussen een organisatie en haar 'belanghebbenden. E-business is het automatiseren van deze interactieprocessen en raakt de gehele waardeketen. Door de snelle acceptatie van internet midden jaren negentig, wordt in veel gevallen gebruikgemaakt van internettechnologie. Een interactieproces wordt vaak aangeduid met de letter 'e-' (e-commerce, e-procurement, e-banking, et cetera).

Externe verslaggeving, voor veel organisaties een belangrijk interactieproces, via internet heeft een grote opmars gemaakt. Met name internationale beursgenoteerde organisaties zien de mogelijkheden van dit medium voor wat betreft het verbeteren van de communicatie met belanghebbenden. De informatie komt voor iedereen direct beschikbaar en de gebruiker bepaalt zelf wanneer hij de informatie wil hebben. Het Britse Accountants Instituut, de ICAEW, publiceerde in 1998 een rapport ${ }^{1}$ over een aantal trends in het rapporteren door grote organisaties. De volgende trends werden gesignaleerd:

\begin{tabular}{|c|c|}
\hline \multicolumn{2}{|c|}{ Figuur 1. Trends in rapporteren } \\
\hline Rapporteren 'oude stijl' & Rapporteren 'nieuwe stijl' \\
\hline Focus op aandeelhouders & - Focus op belanghebbenden \\
\hline Verslaggeving op papier & - Verslaggeving via internet \\
\hline Standaardinformatie & - Informatie op maat \\
\hline Periodiek & - Continue \\
\hline Financieel & $\begin{array}{l}\text { - Uiteenlopende 'Performance } \\
\text { Indicators' }\end{array}$ \\
\hline Nationaal georiënteerd & - Wereldwijd \\
\hline Eén richting & - Dialoog \\
\hline Historische informatie & - Nadruk op toekomstige waarde \\
\hline Jaarrekeningcontrole & $\begin{array}{l}\text { - Assurance over systemen en } \\
\text { processen }\end{array}$ \\
\hline Statische systemen & - Dynamische modellen \\
\hline
\end{tabular}


Opvallend aan deze trends is dat geconstateerd kan worden dat ruim drie jaar na dato de gesignaleerde ontwikkelingen zich hebben doorgezet. Geen van de trends 'oude stijl' zijn echter volledig vervangen door trends 'nieuw stijl'. Het proces van de externe verslaggeving eindigt bij veel organisaties bij de drukker of het postkantoor; het jaarverslag wordt op papier aan de belanghebbenden toegezonden.

In dit artikel zal een overzicht worden gegeven van een ontwikkeling op het gebied van elektronische verslaggeving genaamd XBRL, een op XML gebaseerde taal. In de volgende paragraaf wordt de huidige praktijk rondom internetverslaggeving besproken. Paragraaf 3 gaat in op de werking van XML en de toepassing van XML op het verslaggevingsproces; XBRL. In paragraaf 4 zullen de voordelen van XBRL worden besproken vanuit twee gezichtspunten: informatieverstrekking en informatiegebruik.

Dit artikel kent een belangrijke beperking; omdat XBRL nog in volle ontwikkeling is, zijn er weinig praktische toepassingen bekend.

\section{Internetverslaggeving}

In een discussierapport van de International Accounting Standards Board (IASB), genaamd 'Business Reporting on the Internet ${ }^{2}$, worden drie stadia van internetverslaggeving onderscheiden. Stadium éen betreft het publiceren van financiële informatie in $\mathrm{PDF}^{3}$-formaat. In stadium twee wordt gebruikgemaakt van $\mathrm{HTML}^{4}$ voor het presenteren van financiële informatie. In stadium drie wordt gebruikgemaakt van meer geavanceerde toepassingen, zoals het gebruik van multimedia en de mogelijkheid om financiële analyses uit te voeren.

Uit het IASB-onderzoek blijkt dat het merendeel van de ondernemingen zich in stadium één en twee bevindt. Dit beeld wordt bevestigd door verschillende andere onderzoeken ${ }^{5}$. Slechts enkele organisaties weten de mogelijkheden van stadium drie te benutten. Buiten het formeel publiceren van een retrospectief financieel jaarverslag maken zij gebruik van de mogelijkheden die internettechnologie hun biedt. Bijvoorbeeld via een specifiek voor dit doel ingericht deel van de internetsite ${ }^{6}$, waar medewerkers, investeerders, financieel analisten en milieugroeperingen toegang hebben tot een uitgebreide set aan (financiële) performance indicatoren. Buiten de financiële informatie vindt men er een uitgebreide set aan operationele performance en risico-indicatoren, verder aangeduid met bedrijfsinformatie (vertaling van 'business reporting ${ }^{7}$ ).
Door een betere vergelijkbaarheid leidt toepassing van de International Accounting Standards tot een verbetering van de kwaliteit van de financiële verslaggeving. Een eenduidige accounting-standaard geeft gebruikers in beginsel de mogelijkheid tot daadwerkelijke financiële vergelijking en analyse ${ }^{8}$. De feitelijke bruikbaarheid van de financiële informatie die via internet kan worden verkregen, is door het gebruik van HTML en PDF echter beperkt. Geen van deze formaten is geschikt om geautomatiseerd te worden verwerkt. Willen belanghebbenden gebruikmaken van de informatie om er bijvoorbeeld eigen analyses of vergelijkingen op uit te voeren, dan moeten zij de data opnieuw in hun eigen analyse-applicaties invoeren. Door het ontbreken van structuur en context is het vinden van (bedrijfs)informatie een tijdrovende en vaak frustrerende aangelegenheid. Internet wordt daarom vaak ervaren als een enorme hoeveelheid ongeordende informatie?

Het ontbreken van een technische standaard beperkt de mogelijkheid om financiële informatie via internet eenvoudig te bereiken en te vergelijken.

\section{XML en XBRL}

$\mathrm{XBRL}^{10}$, eXtensible Business Reporting Language, heeft de potentie om voor deze problemen een oplossing te bieden. Met behulp van XBRL kan een organisatie gestructureerd en op elektronische wijze bedrijfsinformatie uitwisselen met haar omgeving. De bedrijfsdata wordt gescheiden van de vorm waarin wordt gerapporteerd en door gebruik te maken van een vaste structuur (afspraken worden vastgelegd in een zogenaamde 'taxonomie') ontstaat voor een gebruiker de mogelijkheid om een XBRL-document direct in de eigen applicatie te verwerken.

XBRL is gebaseerd op XML. Rondom XML worden vele standaarden gecreëerd, waarvan een aantal dominante standaarden. Voorbeelden hiervan zijn eBXML (eBusiness XML voor commerciële transacties), NewsML voor het uitwisselen van nieuwsberichten en XBRL. De ontwikkeling van XBRL wordt gecoördineerd door XBRL.org, een internationaal consortium dat eind 1999 is opgericht op initiatief van de Amerikaanse accountantsorganisatie 'American Institute of Certified Public Accountants (AICPA)'. In het XBRLconsortium $^{11}$ zijn ongeveer 150 organisaties vertegenwoordigd uit alle lagen van de financiële informatieketen.

XML staat voor eXtensible Markup Language en is een uitbreidbare en flexibele opmaaktaal. XML is te 
beschouwen als de intelligente 'neef' van het vertrouwde HTML (HyperText Markup Language), de huidige opmaaktaal van het World Wide Web. De kern van XML zit in de mogelijkheid informatie te structureren en de gestructureerde informatie te scheiden van de vorm waarin het wordt gepresenteerd. De basis van XML wordt gevormd door deze drie-eenheid, de afspraak (taxonomie), de gegevens (het document) en de conversieregels voor de presentatie (de stylesheet).

\subsection{Taxonomie}

Een taxonomie is een beschrijving van alle mogelijke elementen waarover gerapporteerd kan worden. Tussen de elementen in een financieel document, bijvoorbeeld een jaarrekening, bestaan vele relaties. Daarom worden in een taxonomie eveneens de structuur en de onderlinge relaties vastgelegd.

De wijze waarop het management gebruik wenst te maken van een taxonomie, is in beginsel vrij. Uitzondering hierop is als een derde partij, bijvoorbeeld een toezichthouder, een periodieke XBRL-rapportage verlangt. Er zal dan vaak een taxonomie worden voorgeschreven.

Er bestaan twee categorieën taxonomies: generieke, zoals de IAS basistaxonomie, en bedrijfsspecifieke. De creatie van generieke taxonomieën wordt gestuurd door de aanwezigheid van een belangrijke accountingstandaard. Generieke taxonomies zijn te vinden op het internet en kunnen vrij worden gebruikt. Voor specifieke doeleinden kan een taxonomie eventueel eenvoudig worden aangepast of worden gecreëerd.

\subsection{XBRL-document}

Het XBRL-document is een afgeleide van de taxonomie en bevat de feitelijke gestructureerde data, zoals deze zijn beschreven in de taxonomie. Het XBRLdocument bevat geen specifieke opmaak, het bevat alleen de data. De stylesheets worden gebruikt om de data op een bepaalde manier te presenteren en om te vormen in een gewenst uitvoerformaat.

\subsection{Stylesheet}

Een stylesheet bevat een beschrijving van de presentatie en conversieregels. Hierdoor kan een XBRL-document op oneindig veel verschillende manieren worden gepresenteerd: als een opsomming van financiële feiten op de website, een specifiek financieel verslag voor de bank of als een belastingaangifte. Een stylesheet kan eveneens diverse afgeleide bestanden aan- maken, zoals bijvoorbeeld een ander XML-bestand, een printbestand (PDF), een op het web bruikbaar bestand (HTML), et cetera.

Hierdoor ontstaat de mogelijkheid om uit één dataset rapportages voor verschillende gebruikers aan te maken. Dit betekent een aanzienlijke vermindering van de tijd en inspanning die nodig is voor het adhoc verzamelen, formatteren en consolideren van gegevens en het samenstellen van rapporten voor de verschillende belanghebbenden. Indien het management dit wenst, bestaat de mogelijkheid de gebruikers voor een deel zelf hun rapportages te laten samenstellen ('virtual documents').

\section{XBRL en verslaggeving}

XBRL heeft invloed op de wijze waarop de organisatie communiceert met haar belanghebbenden, de verslaggevingsprocessen en de hierbij gebruikte systemen. De complexiteit van een XBRL-toepassing is onder meer afhankelijk van de partij die XBRL gebruikt. Betreft het een rapporterende partij of een relevante gebruiker? In figuur 2 is een overzicht opgenomen van de verslaggevingketen. Deze loopt van de interne rapportages voor het meten en sturen van de bedrijfsprocessen, via de feitelijke informatieverstrekking aan de derden tot aan de informatiegebruiker. In de volgende paragrafen zal worden ingegaan op de laatste twee: de informatieverstrekking en de informatiegebruiker.

\subsection{Informatieverstrekking}

Het samenstellen van een rapportage ten behoeve van een relevante gebruiker kost een organisatie veel tijd. De noodzakelijke informatie komt uit vele bronnen binnen een organisatie. Grote organisaties kennen vaak verschillende administratieve systemen waaruit de financiële en andere informatie wordt gehaald. Deze informatie moet worden verzameld en geconsolideerd, bewerkt en van een aanvullende toelichting worden voorzien. Dit proces dient vervolgens voor de bank, de Kamer van Koophandel, de Belastingdienst en voor elke andere partij die een formele rapportage verlangt, te worden herhaald. Met behulp van XBRL wordt dit proces voor een belangrijk deel geautomatiseerd.

In figuur 2 wordt een overzicht gegeven van het rapportageproces met behulp van XBRL. De interne databronnen worden gekoppeld aan de gewenste taxonomie. Periodiek wordt een XBRL-document opgebouwd. De gekozen periodiciteit is afhankelijk van de wens van het management. De mogelijkheden 
variëren van real-time tot eenmaal per jaar. Met behulp van stylesheets wordt vervolgens voor iedere relevante gebruiker een rapportage gecreëerd.

Het toepassen van XBRL leidt tot een aanzienlijke vereenvoudiging van het rapportageproces. Deze vereenvoudiging levert zowel besparingen op aan de zijde van de informatieverstrekkende partij als aan de zijde van de informatiegebruikende partij. Door gebruik te maken van een centrale gegevensbron verbetert men de transparantie. Doordat de gegevens maar eenmaal worden ingevoerd, wordt de kans op fouten verkleind.

Er zijn verschillende mogelijkheden ten aanzien van het data-aggregatieniveau waarop XBRL-koppeling kan worden aangebracht. De meest complexe en bewerkelijke oplossing is zonder meer het aanbrengen van de XBRL-koppeling op het transactieniveau. Dit scenario is met de huidige techniek echter te complex en op korte termijn niet realistisch.

De meest eenvoudige oplossing is de taxonomie-elementen te koppelen op het niveau van de saldibalans, het hoogste aggregatieniveau. Hierdoor wordt slechts een beperkt aantal voordelen voor de rapporterende organisatie gerealiseerd. Omdat gebruikers de rapportage direct in de eigen systemen kunnen verwerken, ervaren zij daarentegen wel veel voordelen.

\subsection{Informatiegebruik}

Bij vrijwel alle informatieverwerkende partijen kan XBRL leiden tot een sterk verhoogde efficiency en betrouwbaarheid. Kapitaalverstrekkers en analisten besteden nu veel tijd aan het invoeren en converteren van financiële data in hun eigen analyseapplicaties. Als deze applicaties XBRL-data kunnen verwerken, leidt dit tot een omvangrijke efficiencyslag, met als gevolg dat de investeringsbesluitvorming efficiënter verloopt.

Toezichthoudende instanties (zoals de Pensioen- \& Verzekeringskamer en De Nederlandsche Bank) en de overheid (belastingdienst) kunnen eveneens veel voordeel ondervinden van het toepassen van XBRL. Deze organisaties ontvangen periodiek enorme hoeveelheden financiële informatie, die met behulp van

Figuur 2. XBRL en verslaggeving

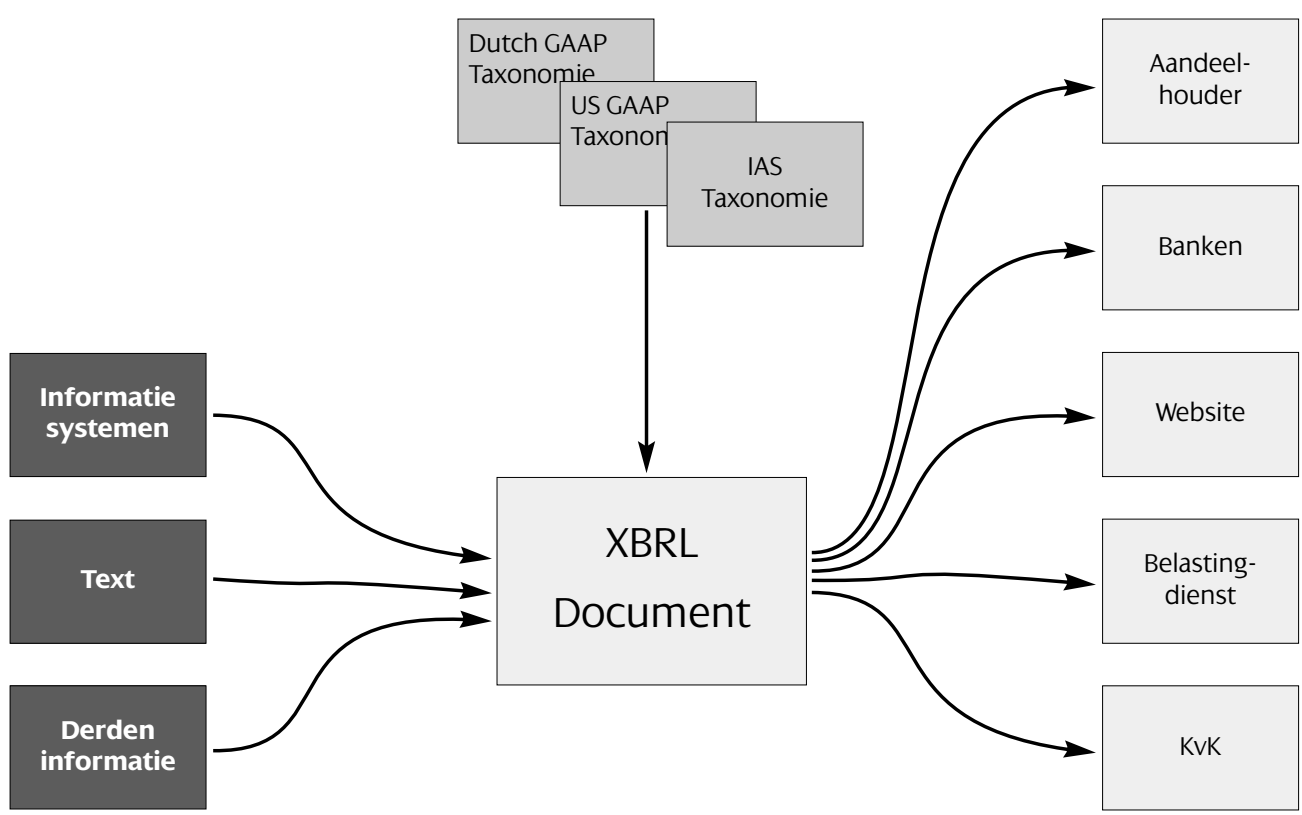

Transacties bedrijfsvoering
Interne rapportages
Externe rapportages
Analyse 
XBRL direct kan worden verwerkt. Veel noodzakelijke analyses en controles met behulp van XBRL kunnen automatisch worden uitgevoerd. Verder kunnen zij eenvoudig een XBRL-taxonomie aan de informatieverstrekkende partijen opleggen.

\section{Slotbeschouwing}

XBRL maakt het mogelijk op elektronische wijze bedrijfsinformatie uit te wisselen. Hierdoor kan, zoals gesteld, het verslaggevingsproces worden vereenvoudigd en versneld. Deze voordelen kunnen worden gerealiseerd in alle delen van de rapportageketen: de informatieverstrekkende partijen en de informatiegebruikende partijen. XBRL kan dan ook een grote invloed hebben op de wijze waarop bedrijfsinformatie door organisaties wordt gestructureerd en gedistribueerd.

Op dit ogenblik zijn er diverse factoren die een snelle implementatie van XBRL in de weg zouden kunnen staan. De eerste betreft het achterliggende verslaggevingsharmonisatieproces. De rapportagestructuur dient te worden vastgelegd in een taxonomie. Om effectieve uitwisseling mogelijk te maken, dient deze te worden geaccepteerd door alle gebruikers. Dergelijke harmonisatieprocessen zijn meestal lange trajecten. De tweede belemmerende factor betreft de complexiteit rondom het ontsluiten van de relevante data. Het volledig automatiseren van het rapportageproces (direct van database naar gebruiker) is mede hierdoor voorlopig een illusie. Maar elke efficiencyslag levert het financieel management tijdwinst op die bijvoorbeeld kan worden besteed aan aanvullende controles en analyses.

Zoals vaak met dergelijke ontwikkelingen lopen de Verenigde Staten voorop. Ook economieën waar de overheid een grote invloed heeft, zoals bijvoorbeeld Singapore, maken snelle voortgang met de implementatie van XBRL. In dergelijke landen is verslaggevingsharmonisatie vaak een eenzijdige 'afspraak' tussen een bepaalde overheidsinstantie en het publiek. Maar het is de verwachting van de auteur dat op korte termijn de contouren van e-reporting ook in Nederland zichtbaar zullen worden.

\section{Literatuur}

Coffin, Z. en N. Hannon, (2002), Introducing XBRL: Decision Making in a Digital Economy, Prentice Hall PTR.

Hannon, N., (2000), XBRL update, Strategic Finance, November.

De Haas, M.A.J. en Ph. Wallage, (2000), Internet dwingt een revolutie af in externe verslaggeving, in: de Accountant, nr. 11, november.

Hoogendoorn M. en G. Mertens, (2001), Kwaliteit van externe verslaggeving in Nederland, Kluwer/Limberg Instituut-reeks.
Lymer A., R. Debreceny, G. Gray en A. Rahman, (1999), Business Reporting on the Internet, IASC discussion paper, november.

Lymer A. en A. Tallberg, (1997), Corporate reporting and the Internet, a survey and commentary on the use of the WWW in corporate reporting in the UK and Finland, research paper gepresenteerd tijdens congres van de European Accounting Association, april.

Overbeek, P., E. Roos en Spruit, (2000), Informatiebeveiliging onder controle, Prentice Hall.

Trites G.D., (1999), The impact of technology on financial and business reporting, CICA research studie, augustus.

Simpson, J., (1998), Just XML, Prentice Hall PTR.

Von Westarp, F., M. Ordelheide, M. Stubenrath, e.a., (1998), Internet-based corporate reporting - filling the standardization gap, IACEW.

Wright I.D., (2000), Parlez-vous XML ou XBRL?, in: Accountancy UK, May.

\section{Noten}

1 The 21st Century Annual Report (The Institute of Charted Accountants England and Wales), November 1998.

2 Discussion Paper IASC staff (Lymer, Debreceny e.a., 1999).

3 Veel gebruikt bestandsformaat voor het uitwisselen van documenten.

4 Hyper Text Markup Language, de taal waarin de meeste internetpagina's zijn opgemaakt. Biedt gebruikers de mogelijkheid om van een stuk tekst naar een ander stuk tekst te springen ('hyperlinking').

5 Lymer, Tallberg, 1997; Deller, Stubenrath, Weber, 1998 en Kolton, Bergman, 2000.

6 Zie bijvoorbeeld 'The Shell Report' (http://www.shell.com/shellreport).

7 Business Reporting is het openbaar publiceren van zowel operationele als financiële gegevens door een onderneming (IASC, 1999).

8 Uit: 20 aanbeveling Limperg Instituut voor externe financiële verslaggeving.

9 Trites, 2000.

10 Voor de technische details: XBRL specificatie (http://www.xbrl.org/ tr/2001/xbrlSampleFilesForSpecv2/main.htm).

11 Het internationale consortium groeit hard. Een actueel overzicht vindt u eveneens op http://www.xbrl.org. 